\title{
Adult hepatic cavernous hemangioma with highly elevated $\alpha$-fetoprotein: A case report and review of the literature
}

\author{
HUAN-YU WANG ${ }^{1}$, LIANG ZHANG ${ }^{2}$, JIAN WU ${ }^{1}$, ZI-JIAN ZHANG ${ }^{1}$, \\ BAO-GANG PENG ${ }^{1}$, LI-JIAN LIANG ${ }^{1}$ and QI ZHOU ${ }^{1}$ \\ ${ }^{1}$ Department of Hepatobiliary Surgery, The First Affiliated Hospital of Sun Yat-Sen University; \\ ${ }^{2}$ Diagnostic Imaging and Interventional Radiology Department, Cancer Center, \\ Sun Yat-Sen University, Guangzhou, Guangdong 510080, P.R. China
}

Received February 11, 2014; Accepted October 22, 2014

DOI: $10.3892 / 01.2014 .2769$

\begin{abstract}
A 47-year-old male presented with a six-month history of fatigue and a four-month history of alanine and aspartate aminopherase elevation. Laboratory examination revealed that the serum $\alpha$-fetoprotein (AFP) level was $371.51 \mu \mathrm{g} / 1$ (normal range, $0-20 \mu \mathrm{g} / \mathrm{l}$ ), and a computed tomography scan revealed a hypodense lesion in the left hepatic lobe. During laparotomy, a dark red-colored soft tumor $(1.5 \times 1.7 \mathrm{~cm}$ in diameter $)$ was found in segment eight of the liver. Intra-operative pathology and post-operative histopathology examinations revealed that the tumor was a hepatic cavernous hemangioma. The serum AFP level was decreased to $24.45 \mu \mathrm{g} / \mathrm{l}$ by the second post-operative week. The literature was searched and only three similar cases were found. A brief review of this rare disease entity was produced, which attempted to explain this appearance reasonably.
\end{abstract}

\section{Introduction}

Among the hepatic vascular tumors, cavernous hemangioma and infantile hemangioendothelioma are benign, while epithelioid hemangioendothelioma and angiosarcoma are malignant. Cavernous hemangioma occurs at all ages, but most frequently in adults, while infantile hemangioendothelioma occurs between birth and 21 years of age (1). $\alpha$-fetoprotein (AFP) is a fetal-specific glycoprotein produced by the fetal liver. Usually, the AFP serum concentration falls rapidly subsequent to birth, while normal adult levels are usually achieved by the age of eight to 12 months. The normal range of AFP for adults and children is variously reported as $<50,<10$ and $<5 \mu \mathrm{g} / 1(2,3)$.

Correspondence to: Professor Qi Zhou, Department of Hepatobiliary Surgery, The First Affiliated Hospital of Sun Yat-Sen University, 58 Zhongshan Second Road, Guangzhou, Guangdong 510080, P.R. China

E-mail: zhouqi@mail.sysu.edu.cn

Key words: hepatic cavernous hemangioma, $\alpha$-fetoprotein, cancer stem cell
Clinically, AFP is one of the indicators that aids in the diagnosis of hepatocellular carcinoma (HCC), particularly for the patients with chronic liver diseases (3-5). There are numerous studies that have reported a higher level of AFP serum exhibiting an increased association with a poor prognosis for patients with HCC $(4,6)$. There are numerous other diseases, excluding $\mathrm{HCC}$, that are also associated with an increased serum AFP level, including fulminant hepatitis, hepatic cirrhosis, gastric cancer and endodermal sinus tumors of the testes, ovaries and extragonadal sites (7-13). As one of the benign neoplasms, the AFP level of hepatic cavernous hemangioma patients is not usually outside the normal range. The present study reports the case of hepatic cavernous hemangioma with a highly elevated AFP level in a 47-year-old male. Written informed consent was obtained from the patient.

\section{Case report}

Patient history. A 47-year-old male was admitted to the Department of Hepatobiliary Surgery (The First Affiliated Hospital of Sun Yat-Sen University, Guangzhou, Guangdong, China) on 14th February 2013 with a six-month history of fatigue and a four-month history of elevated alanine and aspartate aminopherase levels according to colorimetric assay. The patient possessed a 20-year history of chronic hepatitis B with no medical control. In January 2013, the patient was admitted to Dongguan Kanghua Hospital (Dongguan, Guangdong, China) with a five-month history of fatigue.

Examination. During his hospitalization at Dongguan Kanghua Hospital, abdominal computed tomography (CT) scans revealed a tumor located in the right liver, with good enhancement in the arterial and portal venous phases, and multiple cysts in the liver. Magnetic resonance imaging (MRI) revealed a tumor with good enhancement. A diagnosis of hemangioma was considered, but hepatocellular carcinoma could not be excluded. On 4th February, abdominal sonography in the outpatient clinic of The First Affiliated Hospital of Sun Yat-Sen University revealed a solid nodule located in segment eight of the liver, multiple cysts in segments 2, 4 and 5 of the liver, calcification in segment six of the liver and multiple gallbladder polyps. The serum level of AFP was $371.51 \mu \mathrm{g} / 1$ (normal range, 0-20 $\mu \mathrm{g} / \mathrm{l}$ ). 
Table I. Result of laboratory tests.

\begin{tabular}{|c|c|c|c|}
\hline Laboratory test & On admission & Post-operative week four & Reference range \\
\hline Alanine aminotransferase (U/l) & $300 \uparrow$ & 35 & $1-40$ \\
\hline Aspartate aminotransferase (U/l) & $390 \uparrow$ & $91 \uparrow$ & $1-37$ \\
\hline Fasting plasma glucose (mmol/l) & 4.6 & 4.9 & $2.9-6.0$ \\
\hline Urea (mmol/l) & 4.4 & 12.1 & $2.9-8.6$ \\
\hline Serum creatinine $(\mu \mathrm{mol} / \mathrm{l})$ & 73 & 102 & $53-115$ \\
\hline Lactate dehydrogenase $(\mathrm{U} / \mathrm{ml})$ & $256 \uparrow$ & $120 \downarrow$ & $114-240$ \\
\hline Gamma-glutamyltransferase (U/l) & $323 \uparrow$ & $101 \downarrow$ & $2-50$ \\
\hline Alkaline phosphatase (U/l) & 98 & 71 & $0-110$ \\
\hline Total protein $(\mathrm{g} / \mathrm{l})$ & 76.4 & 42.3 & $64.0-87.0$ \\
\hline Albumin (g/l) & 37.5 & 32.4 & $35.0-50.0$ \\
\hline Globulin (g/l) & 38.9 & $9.9 \downarrow$ & $20.0-32.0$ \\
\hline Direct bilirubin $(\mu \mathrm{mol} / \mathrm{l})$ & $19.7 \uparrow$ & $29.3 \uparrow$ & $0.5-7.0$ \\
\hline Indirect bilirubin $(\mu \mathrm{mol} / \mathrm{l})$ & $25 \uparrow$ & $25.2 \uparrow$ & $3.0-15.0$ \\
\hline Sodium $(\mathrm{mmol} / \mathrm{l})$ & 139 & 129 & $135-145$ \\
\hline Potassium (mmol/l) & 4.16 & 4.3 & $3.5-5.3$ \\
\hline Hemoglobin $(\mathrm{g} / \mathrm{l})$ & $169 \uparrow$ & 140 & $120-160$ \\
\hline Hematocrit (proportion of 1.0 ) & $0.494 \uparrow$ & 0.28 & $0.110-0.280$ \\
\hline White blood cells (x109/1) & 5.19 & 9.19 & $4.00-10.00$ \\
\hline Platelets $\left(\times 10^{9} / 1\right)$ & 141 & 288 & $100-300$ \\
\hline Mean corpuscular volume (fl) & $96.5 \uparrow$ & $95.9 \uparrow$ & $82-95$ \\
\hline \multicolumn{4}{|l|}{ Markers of viral hepatitis } \\
\hline Hepatitis B surface antigen & + & & \\
\hline Antibody to hepatitis B surface antigen & - & & \\
\hline Antibody to hepatitis $\mathrm{C}$ virus & - & & \\
\hline Hepatitis B e-antigen & + & & \\
\hline Antibody to hepatitis B e-antigen & + & & \\
\hline
\end{tabular}

$\uparrow$ denotes a result higher than the reference range and $\downarrow$ denotes a result lower than the reference range.

Table II. Serum level of tumor markers.

\begin{tabular}{|c|c|c|c|c|c|}
\hline Tumor marker & On admission & $\begin{array}{c}\text { Two days after } \\
\text { operation }\end{array}$ & $\begin{array}{c}\text { One week after } \\
\text { operation }\end{array}$ & $\begin{array}{c}\text { Two weeks after } \\
\text { operation }\end{array}$ & $\begin{array}{l}\text { Reference } \\
\text { range }\end{array}$ \\
\hline AFP (ug/l) & $371.51 \uparrow$ & 180 & 111 & 24.45 & $0.00-20.00$ \\
\hline CEA (ug/l) & $5.59 \uparrow$ & & & & $0.00-5.00$ \\
\hline CA199 (U/ml) & $39.74 \uparrow$ & & & & $0.00-35.00$ \\
\hline CA125 (U/ml) & 14.20 & & & & $0.00-35.00$ \\
\hline
\end{tabular}

$\uparrow$ denotes a result higher than the reference range and $\downarrow$ denotes a result lower than the reference range. AFP, $\alpha$-fetoprotein; CEA, carcinoembryonic antigen; CA199, carbohydrate antigen 199; CA125, carbohydrate antigen 125.

During physical examination, no ascites were detected and the abdomen was tender on palpation. The results of the laboratory tests performed during hospitalization are shown in Table I. Serum levels of tumor markers, including AFP, carcinoembryonic antigen (CEA) and carbohydrate antigen (CA)-199 were out of the normal range (Table II).
CT scans revealed a $1.3-\mathrm{cm}$ well-defined tumor located in segment eight of the liver (Fig. 1), with good enhancement in the arterial and portal venous phases, multiple hypodense cysts in the liver and calcified lymph nodes prior to segment five in the abdominal cavity. The positron emission tomography (PET) study revealed a tumor of low intensity (Fig. 2), multiple 

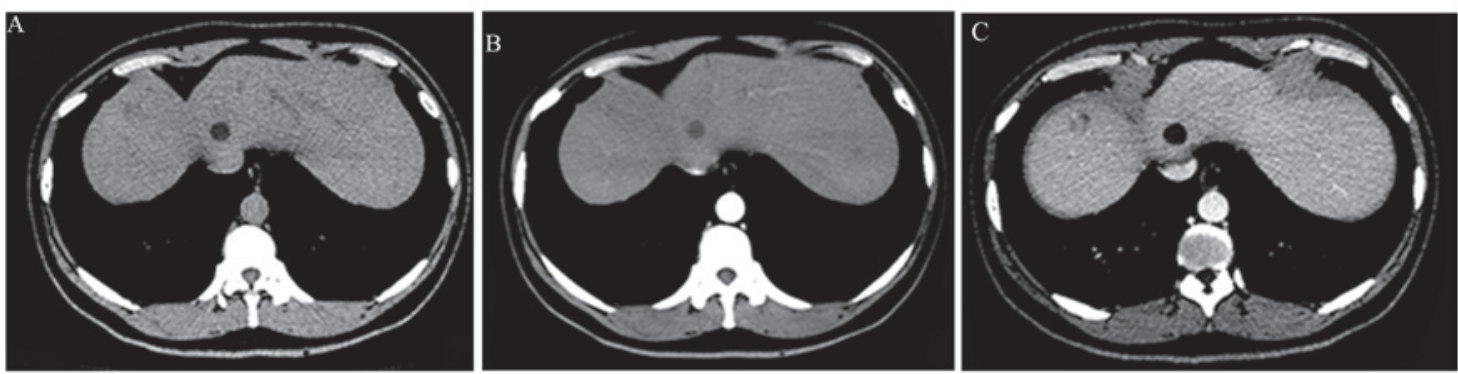

Figure 1. Computed tomography scans revealing (A) a 1.3-cm well-defined tumor in segment eight of the liver. The tumor presents (B) punctate enhancement in the early phase while (C) the enhancement becomes stronger in the delayed phase.

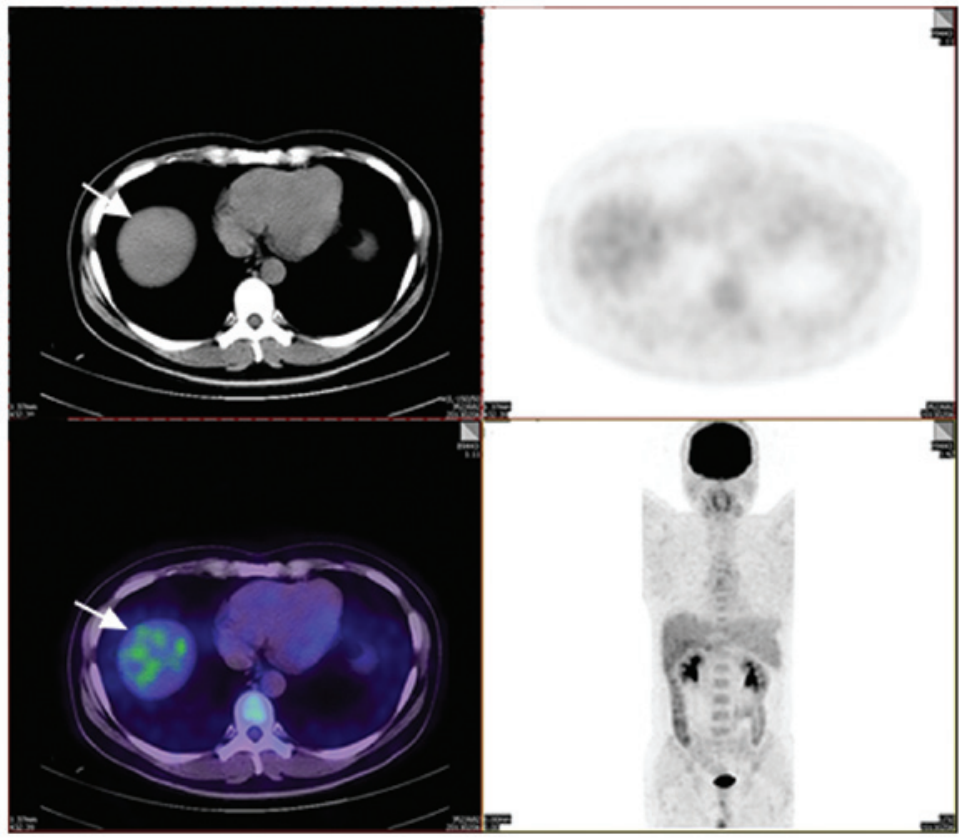

Figure 2. Positron emission tomography revealing a tumor (arrow) of low intensity with a mildly active metabolism in segment eight of the liver.



Figure 3. Histopathology examinations revealing that the tumor was a cavernous hemangioma of the liver (hematoxylin and eosin stain; magnification, $\mathrm{x} 40)$.

hypodense cysts and multiple gallbladder polyps. Due to the age of the patient, the presence of a hepatic hypodense lesion resembling a tumor and the high tumor marker levels, the differential diagnosis comprised hepatocellular carcinoma, focal nodular hyperplasia and hemangioma. To exclude hepatocellular carcinoma, a typical hepatectomy was recommended to remove segment eight of the liver and gall bladder.

Treatment. Exploratory laparotomy was performed on 18th February 2013, and a dark red-colored soft tumor $(1.7 \times 1.5 \mathrm{~cm}$ in diameter) in segment eight of the liver was revealed. Intra-operative ultrasound examination was performed, which identified no other lesions in the remaining sections of the liver. Intra-operative pathology and post-operative histopathology examinations revealed that the tumor was a cavernous hemangioma of the liver (Fig. 3). The serum AFP level had decreased to $111 \mu \mathrm{g} / \mathrm{l}$ by post-operative day seven and to $24.45 \mu \mathrm{g} / 1$ by post-operative week two.

\section{Discussion}

Cavernous hemangioma is the most common hepatic vascular tumor in adults (1). However, the carcinoma biomarkers of hemangioma are usually within the normal range $(2,14,15)$. The abdominal ultrasound examination and CT scan performed on the present patient revealed a localized hepatic nodule with 
the characteristics of hepatic hemangioma, while the highly elevated AFP and CEA levels suggested HCC. However, the intra-operative pathology and post-operative histopathology examinations revealed a liver cavernous hemangioma. The literature was searched and only three cases were found, one in English and the other two in Chinese (14,15). All the patients in the previously reported cases were Chinese, consisting of one male and two females. All three cases were diagnosed following a routine health examination and were negative for the hepatitis B surface antigen. Their pre-operative AFP levels were 1890, 784 and $224 \mu \mathrm{g} / 1$, respectively, and returned to normal levels (0-20 $\mu \mathrm{g} / \mathrm{l})$ within four weeks of the surgical removal of the tumor. The tumors were not located in the same segments, but the three reported cases were all $>6.0 \mathrm{~cm}$ in diameter. The majority of cases occurred as a single mass and were clinically asymptomatic. CT scans revealed all reported cases to possess well-defined nodular lesions, with a good enhancement in the arterial and venous phases following contrast injection. All cases were diagnosed as hepatocellular carcinoma, focal nodular hyperplasia or cavernous hemangioma prior to pathological examination.

These studies suggest that the production of AFP originates from hepatic hemangioma, implying that certain hepatic cavernous hemangioma may possess the ability to synthesize and secrete AFP. For the present patient, the serum AFP level decreased rapidly following hepatectomy. With a 20-year history of chronic hepatitis and an elevated level of tumor markers, the current case prompts consideration of cancer stem cells, which exhibit distinct proliferative and differentiative capacity (16). Although this patient possessed a 20-year history of chronic hepatitis B, which could be a possible reason for elevated serum AFP, the existence of cancer stem cells should not be excluded. According to certain studies into cancer stem cells, it is likely that AFP, CEA and CA199 were produced by cancer stem cells in the hemangioma during development (17-19). The history of chronic hepatitis could concurrently promote the appearance of hepatic cancer stem cells (20-22).

Once a liver lesion with elevated AFP level is found, it is important to differentiate whether the liver lesion is HCC or not. The treatment choice should be based on the nature and extent of disease, so that surgery depends on the surgical risk and the benefit.

In conclusion, clinicians should be aware that there are certain tumors besides HCC and endodermal sinus tumors, such as hepatic cavernous hemangioma, that may produce AFP in adults.

\section{Acknowledgements}

Financial support was provided for the present study by the Program Sci-tech Research Development of Guangdong Province (no. 2012B061700090), the Science and Technology Program of Guangzhou (no. 201300000187) and the Science and Technology Program of Huizhou Daya Bay (national) economic and technological development zone (no. 2013A01016).

\section{References}

1. Ishak KG, Anthony PP, Niederau $\mathrm{C}$ and Nakanuma $\mathrm{Y}$ : Mesenchymal tumours of the liver. In: World Health Organization Classification of Tumors. Pathology and Genetics of Tumours of the Digestive System. Hamilton SR and Aaltonen LA (eds.) IARC Press, Lyon, France, pp191-198, 2000.

2. Ball D, Rose E and Alpert E: Alpha-fetoprotein levels in normal adults. Am J Med Sci 303: 157-159, 1992.

3. Abu El Makarem M: An overview of biomarkers for the diagnosis of hepatocellular carcinoma. Hepat Mon 12: e6122, 2012.

4. Yan D, He Q, Chen Y, Wang L and Zhang X: Detection of $\alpha$-fetoprotein and glypican-3 mRNAs in the peripheral blood of hepatocellular carcinoma patients by using multiple FQ-RT-PCR. J Clin Lab Anal 25: 113-117, 2011.

5. Liu C, Xiao GQ, Yan LN, et al: Value of alpha-fetoprotein in association with clinicopathological features of hepatocellular carcinoma. World J Gastroenterol 19: 1811-1819, 2013.

6. Biondi A, Malaguarnera G, Vacante M, et al: Elevated serum levels of Chromogranin A in hepatocellular carcinoma. BMC Surg 12 (Suppl 1): S7, 2012.

7. Miller RR, Champagne K and Murray RC: Primary pulmonary germ cell tumor with blastomatous differentiation. Chest 106: 1595-1596, 1994

8. Shimada H, Noie T, Ohashi M, Oba K and Takahashi Y: Clinical significance of serum tumor markers for gastric cancer: a systematic review of literature by the Task Force of the Japanese Gastric Cancer Association. Gastric Cancer 17:26-33, 2014.

9. Abdel-Rahman M, Saad Y, El-Raziky M, et al: Hepatitis C genotype 4 with normal transaminases: Correlation with fibrosis and response to treatment, a cohort Egyptian study of 4277 patients. Clin Res Hepatol Gastroenterol 37: 479-484, 2013.

10. Wang L, Zhong Y, Sun L, et al: Clinical and pathological features of hepatoid carcinoma of the ovary. World J Surg Oncol 11: 29, 2013.

11. Tong HL, Dong ZN, Wen XY, et al: Impact of chronic kidney disease on serum tumor markers concentrations. Chin Med J (Engl) 126: 274-279, 2013.

12. Valentino F, Torchio M, Morbini P and Danova M: Synchronous presentation of hepatoid alpha-fetoprotein-producing lung cancer and colorectal adenocarcinoma. Tumori 98: 130e-134e, 2012.

13. Paradies G, Zullino F, Orofino A and Leggio S: Unusual presentation of sacrococcygeal teratomas and associated malformations in children. Clinical experience and review of the literature. Ann Ital Chir 84: 333-346, 2013.

14. Han SL, Wu XL, Jia ZR and Wang PF: Adult hepatic cavernous haemangioma with highly elevated alpha-fetoprotein. Hong Kong Med J 16: 400-402, 2010.

15. Wang ZG, Ding FQ, Zhang AL and Liu GZ: Hepatic hemangioma associated with AFP elevation: two case reports. Qilu Zhongliu Zazhi 4: 153, 1997 (In Chinese).

16. Visvader JE and Lindeman GJ: Cancer stem cells in solid tumours: accumulating evidence and unresolved questions. Nat Rev Cancer 8: 755-768, 2008

17. Stovold R, Blackhall F, Meredith S, et al: Biomarkers for small cell lung cancer: neuroendocrine, epithelial and circulating tumour cells. Lung Cancer 76: 263-268, 2012.

18. Liu J, Zheng M, Tang YL, Liang XH and Yang Q: MicroRNAs, an active and versatile group in cancers. Int J Oral Sci 3: 165-175, 2011.

19. Sasaki N, Ishii T,Kamimura R, et al: Alpha-fetoprotein-producing pancreatic cancer cells possess cancer stem cell characteristics. Cancer Lett 308: 152-161, 2011.

20. Wang C, Yang W, Yan HX, et al: Hepatitis B virus X (HBx) induces tumorigenicity of hepatic progenitor cells in 3,5-dieth oxycarbonyl-1,4-dihydrocollidine-treated $\mathrm{HBx}$ transgenic mice. Hepatology 55: 108-120, 2012.

21. Arzumanyan A, Friedman T, Ng IO, et al: Does the hepatitis B antigen $\mathrm{HBx}$ promote the appearance of liver cancer stem cells? Cancer Res 71: 3701-3708, 2011.

22. Sun YL, Yin SY, Xie HY, et al: Stem-like cells in hepatitis B virus-associated cirrhotic livers and adjacent tissue to hepatocellular carcinomas possess the capacity of tumorigenicity. J Gastroenterol Hepatol 23: 1280-1286, 2008. 